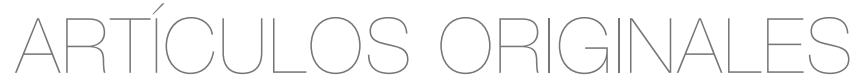

\title{
Administradores de las sociedades mercantiles, su trascendencia procesal
}

\author{
MARTIN EDUARDO PÉREZ CÁZARES*
}

* Doctor en Ciencias Políticas y Sociales, Doctor en Derecho. Profesor investigador. Universidad de Guadalajara, Guadalajara, México. E-mail: mperezcazares@yahoo.com.mx. ORCID: oooo-0oo3-1427-278X. Google Scholar: https://scholar.google. com/citations?hl=es\&user=SS2N7AYAAAAJ. 
COMO CITAR ESTE ARTÍCULO How to cite this article:

Pérez, M. (2019).

Administradores de las sociedades mercantiles, su trascendencia procesal. Revista Perspectiva Empresarial, 6(2), 109-122.

Recibido: 15 de enero de 2019

Aprobado: 08 de julio de 2019
RESUMEN La ciencia administrativa no solo conlleva a dirigir una sociedad mercantil sino a regirse por un orden preestablecido, tanto al interior como al exterior de la misma, en el que el administrador juega un papel de gran importancia. Esto nos lleva a ver aspectos de organización, representación, decisión, gestión y ejecución donde el derecho está presente como parte importante en la consecución del objeto social de la sociedad mercantil. En este texto nos enfocamos en el análisis del aspecto jurídico procesal como parte de la aplicación de normas en la administración de la sociedad, su naturaleza jurídica, sus funciones, sus obligaciones y responsabilidades.

PALABRAS CLAVE administrador, administración, teorías, procedimiento, órganos, responsabilidades.

\section{Management of business entities: Its procedural transcendence}

ABSTRACT Management science does not only lead to managing a business entity but also to complying with a pre-established order, both internally and externally, where the manager plays a role of great importance. In this sense, there are organizational, representation, decision-making, management and execution aspects in which the legal aspect is present as an important part in achieving the company's corporate purpose. In this context we focus on the analysis of the legal procedural aspect as a part of the application of regulation in the management of the company, its legal nature, its functions, its obligations and responsibilities.

KEY WORDS Manager, management, theories, procedure, organs, responsibilities. 


\section{Administradores das sociedades mercantis, sua transcendência procesual}

RESUMO A ciência administrativa não só implica dirigir uma sociedade mercantil senão a reger-se por uma ordem pré-estabelecido, tanto ao interior como ao exterior da mesma, no qual o administrador joga um papel de grande importância. Isto nos leva a ver aspectos de organização, representação, decisão, gestão e execução onde o direito está presente como parte importante na consecução do objeto social da sociedade mercantil. Em este texto nos enfocamos na análise do aspecto jurídico processual como parte da aplicação de normas na administração da sociedade, sua natureza jurídica, suas funções, suas obrigações e responsabilidades. PALAVRAS-CHAVE administrador, administração, teorias, procedimento, órgãos, responsabilidades. 


\section{Introducción}

Uno de los aspectos relevantes de las sociedades mercantiles son los administradores, quienes cumplen un papel protagónico en el cumplimiento de las funciones y objeto de la sociedad puesto que desempeñan un papel tanto jurídico-administrativo como económico con poder de decisión y de representación dentro de la sociedad.

Si bien la cuestión de los administradores de las sociedades mercantiles es más estudiada por las ciencias económico-administrativas, no escapa su estudio al ámbito del derecho dado que su actuar recae en lo jurídico; y en la mayoría de las ocasiones son los que representan a la sociedad en los juicios de que forman parte, tendientes a la aplicación del derecho procesal mercantil.

Desde el punto de vista jurídico realizan actos tendientes a materializar el objeto de la sociedad y los fines de esta, lo que implica que genere obligaciones y derechos para ella o se constituya en acreedor. Muy aparte, de que tienen que proteger el interés social como protección de un bien jurídico por el cual fue contratado.

Desde el punto de vista administrativo debe determinar la política empresarial a seguir al estipular metas y objetivos a corto, mediano y largo plazo, así como estar al pendiente de los asuntos contables, técnico-productivos, publicitarios, mercadológicos entre otros.

Desde el punto de vista económico conlleva a tener ganancias en la actividad comercial que realice a través de ventas o servicios, acaparando el mercado con la idea de dar plusvalía a las acciones y por lo tanto el crecimiento económico de la sociedad.

Así, en palabras de Sabogal (2010):

la sociedad como persona jurídica presenta una necesaria separación entre quien tiene el interés de realizar determinadas operaciones en un mercado (la sociedad) y la persona que efectivamente ostenta la potestad de gestionar y dirigir en interés ajeno esas operaciones (el administrador). (p. 126)
Posición respaldada por Borgioli (1982), al decir que:

esa separación obedece fundamentalmente a dos motivos: i) por una razón de "necesidad", $\mathrm{y}$ es que las sociedades deben confiar su administración a personas que sean verdaderamente capaces y competentes para ejercer tales funciones, pues es evidente que en muchos casos los socios no poseen esas características; y, ii) Por una razón "práctica" y es que no resulta muy viable desarrollar de forma eficiente una administración en la que todos los socios puedan participar en ella, situación que sería particularmente difícil o incluso imposible cuando el número de socios es muy amplio. (p. 28)

\section{Concepto de administrador}

"La administración puede considerarse en sentido técnico o en sentido jurídico; también se distingue entre actos materiales de administración" (Rojina, 1977, p. 78).

Como lo he manifestado, las sociedades mercantiles no solo son agentes económicos ni sociales sino que son generadoras de actos jurídico-mercantiles que ciertamente crean derecho; en donde su actividad va más allá de una situación económica o de un aspecto social al ser un componente jurídico-procesal conformado por un organigrama de personas cuya función forma parte de un engranaje y mecanismo interno (procedimiento) diverso entre cada una de ellas, pero tendientes a hacer funcionar a la sociedad mercantil como la empresa que es en razón de sus fines u objeto social.

Así pues, "la administración incluye la conducción y realización de todos los negocios de la sociedad, bajo un sistema jerarquizado con concentración y delegación de facultades de decisión y con responsabilidad propia" (Acosta y Lara, 2003, p. 379).

La administración implica una actividad de gestión, la organización del ente administrado y 
el establecimiento de relaciones con las personas (trabajadores, empleados, funcionarios) que la conforman y de una representación en sus relaciones externas al obrar en nombre y por cuenta del representado.

En este sentido "en derecho mercantil el concepto de administrador adquiere singular relevancia, ya que lo es el director de una sociedad anónima, el gerente de una filial de la empresa, el factor de una casa comercial, el síndico de la quiebra, etc." (Rodríguez, 1978, p. 105).

En derecho procesal, según Carnelutti (1944) también en el transcurso del proceso se administra porque "ni el proceso ni ningún otro mecanismo de derecho puede sustraerse a las leyes de la economía" (p. 156). El juez ejerce sobre los bienes del proceso actos de administración: ordenar la remisión de un bien a la parte a la que corresponda; ordenar el secuestro y depósito del bien embargado; disponer la colocación de sellos, inventarios, avalúos entre otros. Aun en el derecho internacional es administrador el que a nombre de un organismo supranacional realiza la gestión o gobierno de territorios disputados, estratégicos, zona de refugiados entre otros.

\section{Para Rodríguez (1994) es:}

actividad interna en la formulación de la voluntad y en la adopción de acuerdos, sin que ello trascienda frente a terceros; la representación vale tanto como uso de la firma social, es decir, como posibilidad de que alguien actúe produciendo, creando o extinguiendo relaciones jurídicas cuyos efectos recaerán sobre la sociedad representada. (p. 129)

Mientras que para Barrera (2000) "es la persona que se ocupa tanto de la administración de la empresa, su funcionamiento adecuado y oportuno, como el cumplimiento del objeto o finalidad de la sociedad, siendo ejecutor de las resoluciones de la asamblea" (p. 570).

Es así que podemos conceptualizar al administrador como la persona física encargada de velar por el buen funcionamiento de la sociedad para el cumplimiento de su objeto social y las metas trazadas por los socios al actuar con entera lealtad, diligencia y cuidado manejo en su conducción de la empresa, representando a la misma tanto interna como externamente en diversos actos jurídicos e incluso procesales.

\section{Naturaleza jurídica del acto de administrar}

Hay una discusión dentro de la doctrina jurídica en la que se establece la relación del administrador con la sociedad desde el punto de vista contractual o como una relación organizacional. Aunque cabría también preguntarse si existe una relación laboral no solo contractual (para los efectos del derecho civil) u organizacional (para los efectos de la administración).

Quienes han defendido la teoría contractual en su versión tradicional, que entre otras, fue la primera aproximación para resolver la naturaleza jurídica, han sostenido que la relación entre el administrador y la sociedad se encuentra apoyada sobre un "negocio jurídico bilateral de carácter contractual", formado por el cruce de declaraciones de voluntad que se produce en virtud de: el nombramiento por parte de la Junta General, y la aceptación por parte del administrador.

El problema crucial para esta teoría ha sido, sin embargo, definir cuál es el tipo contractual que gobierna esa relación, y en este sentido, se ha sostenido por la doctrina, con interesantes argumentos a favor y en contra, un amplio número de encuadramientos típicos distintos, destacándose entre estos los de quienes opinan que se trata de un contrato de mandato representativo. (Sabogal, 2010, p. 127)

Entretanto, "la función de administración participa de la naturaleza del mandato, pues el administrador actúa en nombre y por cuenta ajena y responsable ante su comitente. En algunas hipótesis, puede lindar con los conceptos de cuasi contrato en general, y de gestión de negocio, más específicamente" (Rojina, 1977, p. 78).

Lo anterior, lo faculta a llevar la representación de toda sociedad mercantil donde podrán realizar todas las operaciones inherentes al objeto de la 
sociedad; a excepción de lo que expresamente establezca la ley y el contrato social. Si se trata de un solo administrador, este debe considerarse que es representante general de la sociedad respectiva con las limitaciones que fije la ley o que establezcan los estatutos de la misma sociedad.

Es decir que la naturaleza jurídica del administrador será la de tener la representación societaria para ejecutar o realizar los actos jurídicos o materiales que le faculten los estatutos de la sociedad, la voluntad de los socios en acuerdo de asamblea general o de cualquier otra norma jurídica.

\section{Atendiendo a su origen,}

la administración puede ser convencional o contractual (el administrador de propiedades que celebra un contrato de derecho civil), cuasi contractual (el gestor de negocios,), legal (el padre que administra los bienes de sus hijos, el tutor legítimo, quien actúa al frente de una administración pública, etc.), (o judicial de una empresa, síndico designado judicialmente,), etc. (Rojina, 1977, p. 79)

A diferencia del mandato, y tratándose de sociedades, la representación no deriva de la voluntad del otorgante si no de la ley y del contrato social. Los administradores son solidariamente responsables ante la sociedad por el incumplimiento de las obligaciones, así como de la realidad de las aportaciones de los socios; en cambio, "en el mandato cuando el mandatario actúa en nombre propio, no responde ante el mandante por el incumplimiento de las obligaciones asumidas por las personas con las que ha contratado" (Galindo, 2013, p. 304).

Por su parte los requisitos para el cargo de administrador o de consejero son los de personal, temporal, revocable y remunerado. En principio pueden ser administradores tanto las personas físicas como las personas morales - para este caso, en particular, cuando una persona moral administra a otro ente jurídico mercantil a través de un contrato de administración (cuestión muy común que se da en la hotelería) pese a que el ejecutor será una persona física-.
En el caso de la sociedades anónimas, sin embargo, los cargos de administrador o consejero y de gerente son personales y no podrán desempeñarse por medio de representante (así lo dispone el artículo 147 de la Ley General de Sociedades Mercantiles); por ello deberá recaer ese nombramiento esencialmente en personas físicas, ya que las personas morales siempre actúan mediante representantes puesto que la distinción de movilidad solo la tiene una persona física.

La teoría orgánica, impulsada originariamente en Alemania -y ampliamente desarrollada en Italia- por los seguidores de la teoría de la realidad de las personas jurídicas. Conforme con esta visión, que en sus orígenes equiparaba la sociedad con la persona física, los "órganos" y "sociedad" son una unidad necesaria, lo que conduce a apreciar a la persona física (administrador) como una parte inescindible de esa persona jurídica por la cual actúa. En este orden, si administrador (entendido como órgano de administración) y persona jurídica (sociedad) son uno solo, debe excluirse cualquier posibilidad de "vínculo" entre ellos, pues es en los órganos, y a través de ellos, donde la voluntad del ente societario se forma y se manifiesta.

La principal crítica que fue planteada a la teoría orgánica cuestionaba que el hecho de que una sociedad actúe a través de sus órganos no explica suficientemente la relación jurídica que gobierna la posición del administrador frente a la sociedad ni frente a terceros, y esto principalmente porque el administrador "persona física", por el mero hecho de pertenecer al órgano de administración, no pierde su personalidad jurídica. Esta crítica condujo a que muy tempranamente se reformulara la teoría orgánica, para afirmar entonces, que donde no existe posibilidad de vínculo es entre la sociedad y el órgano de administración, en la medida que el órgano es en sí mismo la sociedad, aún cuando sea sólo una parte de ésta (el todo no es ya el todo si una parte se le contrapone), más se reconoció que en la medida que la persona física administrador no pierde su personalidad jurídica se debe admitir que pueda existir algún otro vínculo complementario al orgánico 
(aunque no se precisó cuál) entre éste y la sociedad. (Sabogal, 2010, p. 128-129)

En relación a estas dos teorías podremos decir que la organicista puede aplicarse a la relación que se da con el administrador al interior de la sociedad, mientras que la contractualista puede aplicarse a la función que tiene el administrador al exterior de la sociedad.

Al respecto, y tratándose de la administración de la sociedad, cabría la aplicación de otra teoría: la procesalista; pues aun al interior de la sociedad mercantil se establecen diversos procedimientos de producción como de administración y al exterior procedimientos de negociación de los actos comerciales y los procedimientos judiciales del que forma parte (difícilmente podemos encontrar una sociedad mercantil que no estará sujeta a un procedimiento judicial durante su vida activa).

Por lo que valdría la aplicación de una nueva teoría procesal, la del derecho procesal societario. Una rama del derecho procesal mercantil que regule los procedimientos internos y externos de la sociedad mercantil: (i) internos en cuanto a las asambleas, elección del administrador general único, del nombramiento de comisario entre otros; (ii) externos en cuanto a la comercialización de su productos o servicios, en la negociación de sus actos jurídicos, así como en la resolución de sus conflictos jurídicos.

Este derecho procesal societario forma parte del derecho procesal mercantil no como una rama sino como un subsistema del mismo, pero con la especialización de ser aplicado solo a sociedades mercantiles.

\section{Funciones del administrador}

$\mathrm{Si}$ bien las funciones del administrador pueden ser infinitas y de diversa índole, en el presente texto nos enfocamos en las funciones jurídicas como parte del maravilloso mundo de la administración. Para Barrera (2000) "estamos ante una figura sui generis, a la que corresponde gestión, representación legal de la sociedad y ejecución de los acuerdos sociales" (p. 571).

\section{Mientras que para Giuseppe (1978):}

los administradores deben cumplir los deberes que les imponen la ley y el acta constitutiva, con la diligencia de un mandatario como conviene al miembro de un órgano. De no hacerlo, si no se vigilan la marcha general de la gestión y no tratan de evitar actos perjudiciales a la sociedad, etc., cada uno responde solidariamente. (p. 545)

Conforme a lo anterior, estamos ante la presencia de obligaciones de hacer que le imponen tanto la legislación positiva estatal como la normativa interna de la propia sociedad. Estas obligaciones caen no solo en el ámbito de administrar (en cuanto al poder de decisión), sino también en el ámbito legalista (más que contractualista) dado que implica la obligación de hacer valer los estatutos de la sociedad; esto es, de adecuarse y apegarse a ellos y a las normas aplicables del derecho positivo vigente tanto en su actuar interno como externo.

Los deberes de los administradores pueden agruparse en dos grandes categorías: "deberes que se reflejan en las relaciones internas, es decir frente a los socios y a la sociedad, y deberes que se reflejan en el exterior, frente a los acreedores y frente al público en general" (Galindo, 2013, p. 311).

Asimismo, "los administradores tienen que desempeñar su cargo de acuerdo al deber de buena gestión siempre y cuando realicen dentro de las facultades de representación y ejecución que les hayan asignado de acuerdo en el contrato de sociedad" (Galindo, 2013, p. 307).

Su función administrativa debe ser ejercida hacia la optimación de los objetivos sociales de la compañía, por lo que "como consecuencia de sus obligaciones y facultades, se da la responsabilidad de sus actos y decisiones, debido a que la sociedad actúa por medio de estos" (Montiel y Finol, 2007, p. 43). Por consiguiente, tienen un carácter ejecutivo puesto que ejecutan y hacen posible los acuerdos emanados de la asamblea general. 
En relación a la función procesal, el administrador podrá ser el representante legal de la sociedad en un juicio y tendrá todo el deber de cumplir en tiempo y forma los actos procesales tendientes a proteger los intereses de la empresa de acuerdo a la forma en que acuda ante la autoridad judicial (esto es, como representante o como testigo, como actor o como demandado).

De ahí que la función del administrador sea la de cumplir la norma jurídica cuyo desconocimiento conlleva a mecanismos oficiales coercitivos y sanciones. Y se caracteriza por el formalismo en la disposición de deberes de conducta de cada actor societario que se traduce en instrumentos legales.

Por ello se trata de una tendencia intervencionista, pues es el Estado el que juega un papel protagónico en el apuntalamiento de reglas específicas y detalladas de conducta y en la garantía de estas a través de mecanismos efectivos y sanciones fuertes. La justificación de su intervención está en la necesidad de proteger a la sociedad como generadora de empleos, algo que le interesa al Estado. "Como es lógico, este modelo requiere de la fortaleza de los sistemas judiciales encargados de hacer efectivas las disposiciones legales proteccionistas" (Peña, 2015, p. 17).

En síntesis, podemos decir que la función del administrador es polifacética puesto que tiene un gran poder de decisión y de ejecución dentro de la sociedad como de representación de esta.

\section{El subsistema administrativo dentro del derecho procesal}

Las sociedades mercantiles forman parte del sistema del derecho procesal al tener que aplicar normas procesales tanto al interior de la sociedad (en cuanto a su sistema de producción, el proceso interno de selección de personal y la elección del administrador) como al exterior en los procedimientos judiciales del que forman parte.

Para ello requieren de un Estado que les garantice su subsistencia, dándoles seguridad jurídica. Esto significa tener un poder judicial que responda a las exigencias de mecanismos urgentes de solución de controversias, ya que gran parte de las sociedades mercantiles son grandes generadoras de empleos y de producción económica que el Estado debe de conservar.

Ello a través de un poder judicial efectivo que garantice la conservación de la sociedad mercantil puesto que muchos juzgadores no tienen la experiencia para resolver casos tan específicos, pues en algunas ocasiones hay que anular decisiones hechas al interior de la sociedad. Y cabría preguntarse, ¿hasta dónde debe de proteger el Estado a la sociedad mercantil o al inversionista? Disyuntiva que, coincidiendo con Peña (2015), desde el punto de vista económicoestatal, debe prevalecer la protección a la sociedad mercantil puesto que al Estado le interesa el ente mercantil como generador de empleos y de impuestos.

Ahora bien, para los efectos de un sistema judicial efectivo se requiere de un sistema procesal ágil y seguro con normas claras que den certeza en la aplicación de la ley para que no quepa la interpretación y haya rapidez en la solución de conflictos. Esta rapidez puede hacerse a través de la generación de nuevos sistemas procesales que utilicen el uso de las nuevas tecnologías, las cuales son aplicables a las sociedades mercantiles.

\section{Órgano de administración de la sociedad mercantil}

El órgano de administración puede ser individual o plural. En el primer caso se tratará de un gerente único o de un administrador único como en la sociedad anónima. En el segundo caso se tratará de un consejo de administración cuando los dos o más miembros deberán actuar conjuntamente a través de unajunta convocada con los requisitos que marque la ley y los estatutos de la sociedad, con la salvedad de que esta se celebre. En este sentido "son parte consustancial de la sociedad son, como órganos sociales, un medio o instrumento jurídico para que la compañía opere, se manifieste y actúe" (Barrera, 2000, p. 572).

Así, tenemos en las sociedades anónimas $\mathrm{y}$ en las sociedades en comandita por acciones 
que cuando sean dos o más administradores se constituirá el consejo de administración según lo disponen los artículos $143^{1}$ y $208^{2}$ de la Ley General de Sociedades Mercantiles.

Cuando existe la necesidad de nombrar administradores o de removerlos en su caso, la mayoría de los socios (con derecho) lo harán libremente por medio de la asamblea de socios o accionistas según lo dispuesto en el artículo 100 (fracción IV) ${ }^{3}$ de la Ley General de Sociedades Mercantiles; esto es entendible dado que los socios o accionistas son los creadores de la sociedad mercantil y los que aportaron el dinero para generar el inicio de sus actividades; ese nombramiento deberá contemplarse en el acta constitutiva o posteriormente.

En todo caso, el órgano de administración está subordinado a la junta o asamblea de socios que es el órgano supremo que lo designa y que según el informe que les presenten el o los administradores se discutirá (haciéndoles modificaciones o aprobándolo); y en su caso tomaran las medidas que juzguen convenientes para la sociedad (artículo 181, fracción I) ${ }^{4}$, pudiendo revocar al administrador si así lo considera la asamblea.

La salvedad a la remoción del administrador es cuando este sea socio y en el acta constitutiva este prevista su inamovilidad; y solo podrán ser removidos judicialmente por dolo, culpa o inhabilidad, de acuerdo al artículo 39 de la Ley
General de Sociedades Mercantiles, lo que refiere a generar un juicio para probar estos tres supuestos (ello implica estar sujeto a un procedimiento judicial).

Conforme a lo dispuesto en el artículo 151 de la misma ley, se establece un principio general de prohibición para ser administradores o gerentes de una sociedad mercantil y es que hayan sido inhabilitados para ejercer el comercio. Así, están inhabilitados: los corredores; los quebrados que no hayan sido rehabilitados y los que por sentencia ejecutoria hayan sido condenados por delitos contra la propiedad (artículo 12 del Código de Comercio).

Este órgano de la sociedad se convierte en un consejo de administración en el que las decisiones se tomaran de manera conjunta, en caso de discrepancia en la determinación serán los socios mediante asamblea (artículo 45 de la Ley General de Sociedades Mercantiles); dando así el legislador el gran poder de resolución a los socios.

\section{Con base en esto,}

dentro de la sociedad tiene las siguientes características: 1) es un mecanismo de actuación interna y externa; 2) es un órgano necesario y permanente, dotan a la persona jurídica de un querer psíquico; 3) es un órgano autónomo; 4) ejerce tres tipos de competencia,

1 “Cuando los administradores sean dos o más, constituirán el Consejo de Administración.

Salvo pacto en contrario, será Presidente del Consejo el Consejero primeramente nombrado, y a falta de éste el que le siga en el orden de la designación.

Para que el Consejo de Administración funcione legalmente deberá asistir, por lo menos, la mitad de sus miembros y sus resoluciones serán válidas cuando sean tomadas por la mayoría de los presentes. En caso de empate, el Presidente del Consejo decidirá con voto de calidad.

En los estatutos se podrá prever que las resoluciones tomadas fuera de sesión de consejo, por unanimidad de sus miembros tendrán, para todos los efectos legales, la misma validez que si hubieren sido adoptadas en sesión de consejo, siempre que se confirmen por escrito".

2 "La sociedad en comandita por acciones se regirá por las reglas relativas a la sociedad anónima, salvo lo dispuesto en los artículos siguientes".

3 "IV. De hacer el nombramiento de los administradores y comisarios que hayan de funcionar durante el plazo señalado por los estatutos, con la designación de quiénes de los primeros han de usar la firma social”.

4 “La Asamblea Ordinaria se reunirá por lo menos una vez al año dentro de los cuatro meses que sigan a la clausura del ejercicio social y se ocupará, además de los asuntos incluidos en la orden del día, de los siguientes:

I. Discutir, aprobar o modificar el informe de los administradores a que se refiere el enunciado general del artículo 172, tomando en cuenta el informe de los comisarios, y tomar las medidas que juzgue oportunas". 
gobierno, gestión y representación de la sociedad; 5) tiene facultades orgánicas. (Labariega, 2005, p. 274)

\section{Consejo de administración y gerentes}

Se origina cuando de los estatutos de la sociedad mercantil se establece la encomienda a más de una persona física de constituirse en un cuerpo colegiado que tendrá poder de representación de la sociedad, por lo tanto constituye una cuestión normativa interna que bien pueden ser los propios socios o personas extrañas a estos. Así, puede ser creado el consejo de administración desde la constitución de la sociedad o en una asamblea posterior.

El marco legal que ampara el funcionamiento del consejo de administración de la sociedad anónima se encuentra regulado en el tercer párrafo del artículo 143 de la Ley General de Sociedades Mercantiles, el cual establece:

para que el Consejo de Administración funcione legalmente deberá asistir, por lo menos, la mitad de sus miembros, y sus resoluciones serán válidas cuando sean tomadas por la mayoría de los presentes. En caso de empate, el Presidente del Consejo decidirá con voto de calidad.

En este sentido Acosta y Lara (2003) afirman que:

al consejo de administración se le impone de acuerdo al artículo citado el funcionamiento de manera conjunta a más de dos personas, con una serie de normas para la administración colegiada, basada en el predominio de la voluntad de la mayoría, facilitando la adopción de decisiones al mismo tiempo que se asegura una gestión más coordinada y eficiente. (p. 385)

Al respecto, entramos a la conjunción de voluntades donde es necesario armonizar todas las ideas que se manejen en las reuniones de consejo con el propósito de caminar de manera conjunta por el bien de la sociedad; una especie de democracia societaria en la que prevalezca la mayoría de las voluntades.

En el consejo de administración la representación no corresponde a ninguno de los miembros de la sociedad, esta se atribuye al órgano como un todo; esto es un ente dentro de la propia sociedad, aquí podría aplicarse la teoría organista puesto que en forma es un órgano interno de la sociedad. Son excepciones a la representación: (i) la ejecución de actos concretos, es decir, de resolución, adoptados por la asamblea o por el propio consejo; a falta de designación especial, corresponde su ejecución solamente al presidente del consejo (artículo 148 de la Ley General de Sociedades Mercantiles); (ii) que la escritura social o un acuerdo de asamblea, otorguen la representación general o ciertas facultades a alguno o algunos de los miembros y (iii) que se trate de "actos urgentes cuya omisión traiga como consecuencia un daño grave para la sociedad" (artículos 45 (párrafo segundo) y 57 (párrafo segundo) de la Ley General de Sociedades Mercantiles).

En lo que a esto refiere, el consejo de administración corresponde más a una teoría orgánica puesto que es parte de la estructura de la sociedad y comúnmente conforme a los estatutos es el órgano que toma las decisiones; aunque el órgano máximo será la asamblea general de accionistas, constituyéndose así en el gobierno corporativo.

Según la Organización para la Cooperación y el Desarrollo Económico -OCDE- se trata de la relación entre el manejo de una compañía, su junta, sus asociados y otros terceros. El gobierno corporativo provee la estructura a partir de la cual los objetivos de la compañía se llevan a cabo y determina los medios para lograrlos, así como el monitoreo de su cumplimiento.

En el caso de las sociedades anónimas y de las sociedades en comandita por acciones para que el consejo de administración funcione legalmente deberán asistir la mitad de sus miembros, y sus resoluciones serán válidas cuando sean tomadas por la mayoría de los presentes. En caso de 
empate, el presidente del consejo decidirá con un voto de calidad.

En los estatutos podrá preverse que las resoluciones tomadas fuera de sesión de consejo por unanimidad de sus miembros tendrán, para todos los efectos legales, la misma validez que si hubieren sido adoptadas en una sesión de consejo; siempre y cuando que se confirmen por escrito (artículos 143 y 208 de la Ley General de Sociedades Mercantiles).

La asamblea general de accionistas, el administrador o el consejo de administración podrán nombrar uno o varios gerentes generales o especiales ya sean o no accionistas. Los nombramientos de los gerentes serán revocables en cualquier tiempo por el administrador o consejo de administración o por la asamblea general de accionistas (artículo 145 de la Ley General de Sociedades Mercantiles). Esto implica ciertas facultades legales tanto para la asamblea general como para el administrador o el consejo de administración, aunque esta figura administrativa se convierte en un auxiliar del administrador.

Los gerentes tendrán las facultades que expresamente se les confiera. No necesitaran autorización especial del administrador o del consejo de administración para los actos que ejecuten y gozaran dentro de la órbita de las atribuciones que se les haya asignado de las más amplias facultades de representación y ejecución (artículo 146 de la Ley General de Sociedades Mercantiles); de igual manera habría que analizar si las facultades se encuentran establecidas en los estatutos dado que -en mi opinión- sí se necesita un documento que avale las facultades que se le otorgan, mismas que pueden estar establecidas en los estatutos de la sociedad o en un documento necesario para acudir a juicio en representación de la sociedad.

Como ya se mencionó, los cargos de administrador y de gerente son personales; por ello no podrán desempeñarse por representante legal, aunque pueden delegar por poder ciertas facultades que le hayan permitido - lo cual no restringe su función- pudiendo nombrar a personas determinadas para que ejecuten o se encarguen de casos o actos específicos (artículos 42 y 147 a 150 de la Ley General de Sociedades Mercantiles).

\section{Obligaciones del órgano de administración}

Independientemente de las obligaciones establecidas en los estatutos para los administradores, y en las obligaciones que determinen la asamblea general (consideradas esta dos como obligaciones privadas), existen obligaciones legales para los administradores establecidas en la legislación positiva mercantil.

1. La de rendir cuentas semestralmente, "si no hubiere pactado sobre el particular, y en cualquier tiempo en que lo acuerden los socios" (artículo 43 de la Ley General de Sociedades Mercantiles).

2. Presentar a la asamblea de accionistas, anualmente, un informe que incluya por lo menos: (i) un informe de los administradores sobre la marca de la sociedad en el ejercicio, así como sobre las políticas seguidas por los administrados y sobre los principales proyectos existentes; (ii) un informe en que se declaren y expliquen las principales políticas y criterios contables y de información financiera; (iii) un estado que muestre la situación financiera de la sociedad hasta la fecha de cierre de su ejercicio; (iv) un estado que muestre debidamente explicados y clasificados los resultados de la sociedad durante el ejercicio; (v) un estado que muestre los cambios en la situación financiera durante el ejercicio; (vi) un estado que muestre los cambios en las partidas que integran el patrimonio social, acaecidos durante el ejercicio; (vii) las notas que sean necesarias para completar o aclarar la información que suministren los estados anteriores; a todo esto, se agregara el informe antes mencionado (artículo 172 de la Ley General de Sociedades Mercantiles).

3. Convocar a las asambleas de accionistas (artículo 183 de la Ley General de Sociedades Mercantiles). 


\section{Responsabilidades de los administradores}

Dedicarse a la administración supone un cumulo de responsabilidades relacionadas con el cargo, pues son el capitán de un barco llamado sociedad cuyo fin es llevarlo a buen puerto, lo que supone la responsabilidad de sus actos debido a que la sociedad actúa por medio de los administradores.

Los administradores tendrán la responsabilidad inherente a su mandato, y la derivada de las obligaciones que los estatutos y la ley les imponen, según el artículo 157 de la citada ley que plantea:

\begin{abstract}
los Administradores tendrán la responsabilidad inherente a su mandato y la derivada de las obligaciones que la ley y los estatutos les imponen. Dichos Administradores deberán guardar confidencialidad respecto de la información y los asuntos que tengan conocimiento con motivo de su cargo en la sociedad, cuando dicha información o asuntos no sean de carácter público, excepto en los casos en que la información sea solicitada por autoridades judiciales o administrativas. Dicha obligación de confidencialidad estará vigente durante el tiempo de su encargo y hasta un año posterior a la terminación del mismo.
\end{abstract}

Esto implica que tienen un deber de confidencialidad sobre todo en los procesos de producción y que de llegar a quebrantarlo serán sujetos de responsabilidad tanto penal como mercantil, por lo que tendrían que reparar el daño ocasionado a la sociedad.

Por ello deben de conocer los procesos de producción y/o servicios de la sociedad que administran, lo que implica una importancia trascendental en el conocimiento pleno del procedimiento interno que cada sociedad maneja.

Asimismo, los administradores son solidariamente responsables con la sociedad: (i) de la realidad de las aportaciones hechas por los socios; (ii) del cumplimiento de los requisitos legales y estatutarios establecidos respecto a los dividendos que se paguen a los accionistas; (iii) de la existencia y mantenimiento de los sistemas de contabilidad, control, registro, archivo o información que previene la ley; (iv) del exacto cumplimiento de los acuerdos de las asambleas de accionistas, ya que así lo dispone el artículo 158 de la Ley General de Sociedades Mercantiles.

Los administradores alcanzan un gran poder en la sociedad, pero también tienen una gran responsabilidad dado el cumulo de obligaciones que les otorga no solo los estatutos o los acuerdos de asamblea sino la propia ley; esto implica el uso de una discrecionalidad en la toma de decisiones.

En Estados Unidos se ha generado la regla de la discrecionalidad o regla de juicio de los negocios (business judgment rule).

La BJR parte de que, antes que el aparato jurisdiccional del Estado, son los administradores expertos quienes tienen la facultad de tomar las decisiones empresariales de manera discrecional según su propia evaluación del negocio, con la claridad, obviamente, de que deben acomodarlas al cumplimiento de sus deberes. De todas formas, el ajuste de sus actos a estos deberes se presume, con lo que, en caso de alegarse algún tipo de comportamiento oportunista que perjudique los intereses de los asociados o la sociedad, quien lo alegue tiene la gran carga de probar o desvirtuar la presunción. (Peña, 2015, p. 23)

De manera precisa, la regla se concreta en que los administradores de una sociedad se cobijan por la presunción de que sus determinaciones se han ajustado a un juicio prudente y concordante con sus deberes pero siempre con las facultades que se les otorga; ello genera una gran interrogante: ¿hasta dónde pueden ejercer su discrecionalidad en la toma de decisiones cuando están sujetos también a ciertos límites?; al respecto, el artículo 160 de la citada ley afirma: "los Administradores serán solidariamente responsables con los que les hayan precedido, por las irregularidades en que éstos hubieren incurrido si, conociéndolas, no las denunciaren por escrito a los Comisarios". 
Esto es, tendrán que ponerse al tanto de todos los asuntos que hayan hecho los administradores anteriores dentro de la sociedad en cuanto a sus irregularidades; aunque es obvio también que difícilmente van a conocer los errores de la administración pasada para darlos a conocer a los comisarios; esto conlleva a tener que estudiar todo el historial administrativo para poder denunciar anomalías, implicando una responsabilidad compartida (pero de algo que no fueron parte ni cometieron), lo que los sujeta también a cuestiones procesales.

Existiendo una antinomia en la Ley General de Sociedades Mercantiles sobre la responsabilidad de los administradores, pues el artículo 160 establece una responsabilidad compartida con sus anteçesores y el artículo 76 a la vez los exime: "los administradores que no hayan tenido conocimiento del acto o que hayan votado en contra, quedarán libres de responsabilidad".

Ahora bien, el legislador otorgó a la asamblea general de accionistas el monopolio de exigir la responsabilidad a los gerentes. Lo anterior, establecido en el segundo párrafo del artículo 76 de la citada ley:

la acción de responsabilidad en interés de la sociedad contra los gerentes, para el reintegro del patrimonio social, pertenece a la asamblea y a los socios individualmente considerados; pero éstos no podrán ejercitarla cuando la asamblea, con un voto favorable de las tres cuartas partes del capital social, haya absuelto a los gerentes de su responsabilidad.

Mismo monopolio que se otorga en el artículo 161 de esta norma, al señalar: "la responsabilidad de los Administradores sólo podrá ser exigida por acuerdo de la Asamblea General de Accionistas, la que designará la persona que haya de ejercitar la acción correspondiente, salvo lo dispuesto en el artículo $163^{\prime \prime}$.

Exceptuando para los casos de quiebra o concurso mercantil de la sociedad no solo a la asamblea, sino también a los acreedores de la misma una vez declarada esta; en donde será el síndico de la quiebra o concurso mercantil el encargado de ejercitar la acción de responsabilidad al administrador, pues así lo dispuso también el legislador en el tercer párrafo del mismo dispositivo legal: "la acción de responsabilidad contra los administradores pertenece también a los acreedores sociales; pero sólo podrá ejercitarse por el síndico, después de la declaración de quiebra de la sociedad".

La terminación del cargo de administrador procede por razones de muerte, terminación del plazo para el cual hubiera sido designado, por renuncia, por revocación e inhabilitación. También cesaran en el desempeño de su cargo inmediatamente que la asamblea general de accionistas pronuncie resolución de responsabilidad de acuerdo a lo dispuesto en el artículo 162 del mismo cuerpo normativo, al establecer en su segundo párrafo: "los Administradores cesarán en el desempeño de su encargo inmediatamente que la Asamblea General de Accionistas pronuncie resolución en el sentido de que se les exija la responsabilidad en que hayan incurrido".

Esto constituye una falta al principio universal de presunción de inocencia y, por consiguiente, la violación a un derecho humano: ya que se separa a un administrador de su cargo sin antes haber sido juzgado y condenado o sin haber sido oído y vencido en juicio, así de no comprobarse su responsabilidad podría (el administrador) demandar la reparación del daño a la sociedad o a los socios.

\footnotetext{
5 “Los accionistas que representen el veinticinco por ciento del capital social, por lo menos, podrán ejercitar directamente la acción de responsabilidad civil contra los Administradores, siempre que se satisfagan los requisitos siguientes:

I. Que la demanda comprenda el monto total de las responsabilidades en favor de la sociedad y no únicamente el interés personal de los promoventes, y

II. Que, en su caso, los actores no hayan aprobado la resolución tomada por la Asamblea General de Accionistas sobre no haber lugar a proceder contra los Administradores demandados.

Los bienes que se obtengan como resultado de la reclamación serán percibidos por la sociedad". Reformado mediante decreto publicado en el Diario Oficial de la Federación el 13 de junio de 2014.
} 


\section{Conclusiones}

Los administradores de la sociedad deben ser personas polifacéticas dado que tienen en su actuar un cúmulo de obligaciones tanto internas como externas que los lleva de igual manera a la aplicación de normas tanto privadas de la propia sociedad como a las promulgadas por el Estado. Esto es, debe conocer los procesos de producción de la sociedad que administra (su normativa interna establecida en los estatutos) y la legislación estatal para poder ejercer el mandato que les es otorgado.

La administración de una sociedad se basa en procedimientos, por lo que su base primordial es el derecho procesal. De ahí que resulte aplicable una nueva teoría procesal, la del derecho procesal societario; una rama del derecho procesal mercantil que es un subsistema especializado del mismo.

Así pues, establecer responsabilidades a los administradores genera la aplicación de un juicio. Por ello no debe ser separado de su cargo hasta que no sea condenado, en especial en aquellos casos en los que ha depositado fianza. Lo anterior, por la aplicación del principio universal de presunción de inocencia.

\section{Referencias}

Acosta, M. y Lara, J. (2003). Nuevo derecho mercantil. Ciudad de México, México: Editorial Porrúa.

Barrera, J. (2000). Instituciones de derecho mercantil. Ciudad de México, México: Editorial Porrúa.

Borgioli, A. (1982). L'amministrazione delegata. Firenze, Italia: Ed. Nardini.
Carnelutti, F. (1944). Sistema de derecho procesal civil. Buenos Aires, Argentina: Editorial UTEHA.

Galindo, E. (2013). Derecho mercantil. Ciudad de México, México: Editorial Porrúa.

Giuseppe, B. (1978). Instituciones de derecho privado. Ciudad de México, México: Editorial Porrúa.

Labariega, P. (2015). El órgano de administración de la sociedad anónima. Ciudad de México, México: UNAM.

Montiel, M. y Finol, T. (2007). La responsabilidad de los administradores de la sociedad anónima. Telos, 9(1), 42-53.

Peña, M.V. (2015). Gobierno corporativo, oportunismo y abuso del derecho en sociedades mercantiles. Revista de Derecho Privado, 54, 2-49.

Rodríguez, J. (1978). Tratado de sociedades mercantiles. Ciudad de México, México: Editorial Porrúa.

Rodríguez, J. (1994). Derecho mercantil. Ciudad de México, México: Editorial Porrúa.

Rojina, R. (1977). Derecho civil mexicano. Ciudad de México, México: Editorial Porrúa.

Sabogal, L.F. (2010). La relación administrador sociedad. Revista de Derecho Privado, 18, 125-156. 